\title{
The clinical effectiveness of tafluprost on Japanese normal-tension glaucoma patients
}

This article was published in the following Dove Press journal:

Clinical Ophthalmology

\author{
Akio Nomura' \\ Hirotaka Osaki' \\ Fumiki Shimada' \\ Yasuaki Kuwayama ${ }^{2}$ \\ 'Pharmacovigilance, Quality \\ Compliance Division, Santen \\ Pharmaceutical Co., Ltd., Osaka, Japan; \\ ${ }^{2}$ Fukushima Eye Clinic, Osaka, Japan
}

Purpose: This study evaluates the effect of tafluprost on visual field progression in normal-tension glaucoma (NTG) in a Japanese population under daily clinical practice settings.

Patients and methods: This is a post-marketing, multicenter, non-interventional, observational study. Patients with NTG who initiated tafluprost treatment were registered and prospectively observed for 2-3 years to investigate its effectiveness on visual field progression and intraocular pressure (IOP) and safety in Japan. Visual field progression was evaluated using mean deviation (MD) slopes in a visual field analysis set that comprised patients with reliable Humphrey visual fields taken at 5 or more time points throughout the 2-3 years.

Results: Of the 1,454 patients registered from 160 medical institutions, 1,353 were set for safety analysis and 416 were set for visual field analysis. Due to insufficient effectiveness or safety reasons 194 patients discontinued tafluprost, and 388 patients discontinued tafluprost due to being lost to follow-up or another reason. The MD slopes were $-0.09 \pm 0.85 \mathrm{~dB} /$ year in the entire visual field analysis set, $-0.02 \pm 0.80 \mathrm{~dB} /$ year in naïve monotherapy patients, $-0.07 \pm 0.68 \mathrm{~dB} /$ year in switching monotherapy patients, and $-0.32 \pm 1.04 \mathrm{~dB} /$ year in concomitant therapy patients. In naïve monotherapy, a significant difference in MD slopes was observed between patients with an IOP reduction of $10 \%$ or higher $(0.11 \pm 0.73 \mathrm{~dB} /$ year $)$ vs patients with an IOP reduction of $<10 \%(-0.22 \pm 0.87 \mathrm{~dB} /$ year). Significant differences were also observed in the subset analyses when the patients were divided by both MD and IOP at baseline, and presence of vitreoretinal concomitant disease. The adverse reactions were observed in $9.53 \%$ patients without any serious adverse reactions.

Conclusion: An at least 10\% IOP reduction with tafluprost monotherapy in $56.7 \%$ of the treatment-naïve NTG eyes was sufficient to significantly reduce the MD rate of progression.

Keywords: MD slope, NTG, observational post-marketing study, ophthalmology, visual field

\section{Introduction}

Normal-tension glaucoma (NTG) is characterized by visual field loss, secondary to irreversible and progressive optic nerve damage, even though the intraocular pressure (IOP) values remain within the normal range. According to the Tajimi study, an epidemiological survey on glaucoma conducted between 2000 and 2001, the prevalence of glaucoma in the Japanese population aged $\geq 40$ years was estimated to be $5.0 \%$, and $72 \%$ of all glaucoma patients had NTG. ${ }^{1,2}$ IOP reduction is the only treatment that has been scientifically proven to delay the progression of optic nerve damage; ${ }^{3-5}$ and in NTG patients, a slower rate of visual field progression was seen when the IOP was reduced by $30 \%$ in the Collaborative NTG Study (CNTGS). ${ }^{6}$ On the other hand, the distribution of IOP in the CNTGS was higher than that found in Japanese NTG patients; therefore, it is possible that CNTGS may not be applicable to treating Japanese NTG patients. ${ }^{7,8}$ While numerous reports have been published that have used IOP as
Correspondence: Akio Nomura

Santen Pharmaceutical Co., Ltd., 4-20

Ofukacho Kita-ku, Osaka 530-8552, Japan

$\mathrm{Tel}+8$ I 64802933 ।

Fax +81663593843

Email akio.nomura@santen.com
Clinical Ophthalmology 2018:12 539-548 
the endpoint for glaucoma drug treatment, many have not assessed visual field progression as an endpoint.

Prostaglandin analogs are the first-line topical therapy for glaucoma due to their potent IOP-lowering properties. ${ }^{9}$ Tafluprost ophthalmic solution $0.0015 \%$ (hereafter, tafluprost), a prostaglandin analog anti-glaucoma ophthalmic solution, was developed by Santen Pharmaceutical Co., Ltd., Osaka, Japan, and was launched in 2008. In the Phase III clinical study of tafluprost conducted in NTG patients in Japan, tafluprost had a significant IOP-lowering effect compared with placebo. ${ }^{10}$ In post-launch observational studies, which followed for 2 years after treatment initiation, tafluprost showed a favorable IOP-lowering effect and safety profile in the daily clinical practice setting in patients with various types of glaucoma, including NTG. ${ }^{11,12}$

This study evaluated the effect of tafluprost ophthalmic solution $0.0015 \%$ on visual field progression in NTG in a Japanese population under daily clinical practice settings.

\section{Patients and methods Study design}

This study was a post-marketing, multicenter, prospective, non-interventional, observational study. This study started in November 2011 and ended in December 2015. Since the study protocol was reviewed and approved by the Japanese regulatory authorities of Pharmaceuticals and Medical Devices Agency (PMDA) prior to initiation, ethical review and approval were not required for the individual study sites.

This study evaluated the effect of tafluprost ophthalmic solution $0.0015 \%$ on visual field progression in NTG in a Japanese population under daily clinical practice settings.

\section{Study patients and registration}

The inclusion criteria were as follows: 1) NTG diagnosis in at least one eye; 2) no treatment history with tafluprost (Tapros ${ }^{\circledR}$ ophthalmic solution $0.0015 \%$, preserved multidose, Santen Pharmaceutical Co., Ltd.); and 3) existence of visual field data measured with Humphrey perimeter (Humphrey Visual Field Analyzer, Carl Zeiss Meditec AG, Jena, Germany) using 30-2 Swedish Interactive Threshold Algorithm (SITA) standard for the NTG eye(s) within 3 months before tafluprost treatment initiation, and visual field data satisfying all the reliability indices (fixation losses $<20 \%$, false positives $<33 \%$, false negatives $<33 \%$ ) and mean deviation (MD) $\geq-15 \mathrm{~dB}$. In this study, NTG was defined as a kind of open-angle glaucoma characterized by glaucomatous optic neuropathy with IOP measurements that did not exceed 21 $\mathrm{mmHg}$. A central registration system was used for enrollment to eliminate patient selection bias. Informed consent was not obtained, since Japanese regulations do not require informed consent for any post-marketing, non-interventional, observational studies conducted in accordance with the GPSP.

\section{Items for observation and examination}

In this study, only 1 eye of each patient was evaluated for efficacy. If both eyes were eligible, the eye with the worse MD at baseline was selected as the study eye. If both eyes had the same MD at baseline, the right eye was designated as the study eye. The observation period for an individual case was 2-3 years after tafluprost treatment initiation. The observation was terminated if: 1) the tafluprost treatment was terminated; 2) the tafluprost treatment was considered to be interrupted over 28 days; 3 ) an intraocular surgery including laser surgery was conducted; or 4) the scheduled observation period was completed.

The interval of the patient's visit was not determined in the protocol of this study, but it was determined at the physician's discretion in their typical daily clinical settings. The following data were collected: patient baseline characteristics (including sex, age, concomitant diseases, family history of glaucoma, spherical equivalent, and presence/ absence of optic disc hemorrhage), prior medications, tafluprost compliance following treatment initiation, concomitant medications, presence/absence of intraocular surgery, IOP, MD obtained using Humphrey perimeter, presence/ absence of new optic disc hemorrhage, presence/absence of onset/progression of cataract, pregnancy, and adverse events. Biannual measurement of MD was recommended; however, the interval of visual field testing was determined at the physician's discretion. Because any type of intraocular surgery was not allowed during the study period, no postsurgical MD data was contained in the analysis data set of this study.

Treatment patterns were classified according to prior and concomitant medications and were defined as follows: naïve monotherapy: never used other glaucoma medications; switching monotherapy: used one or more glaucoma medications prior to study but only used tafluprost after enrollment; and concomitant therapy: using one or more concomitant glaucoma medications, regardless of presence/absence of any previous glaucoma medications. 
An adverse drug reaction (ADR) was defined as an adverse event for which causality by tafluprost could not be ruled out.

\section{Analysis}

Analysis was performed using SAS (Version 9.2, SAS Institute, Cary, NC, USA). The level of significance was $5 \%$ (two-tailed). Data were expressed as mean \pm SD.

A paired $t$-test was used to analyze the IOP in comparison to the baseline. The starting point of treatment with tafluprost was used as the baseline (month 0). Kaplan-Meier survival curves were used to estimate the persistency rates of tafluprost at 12, 24, and 36 months with $95 \%$ CI. Patients whose reasons for discontinuation of tafluprost were lost to follow-up or another reason other than the insufficient efficacy and safety of the drug were regarded as censored observations. MD slopes were calculated using linear regression analyses, and the values were shown with $95 \% \mathrm{CI}$. MD slopes were calculated only for patients who had MDs that satisfied the reliability indices in the testing protocol and who had a Humphrey visual field 30-2 analyzed by the SITA standard algorithm. These visual field examinations also had to be performed at 5 time points or more in the period of 2-3 years. A differential analysis of MD slopes was performed using one-way analysis of variance.

\section{Compliance with ethical guidelines}

This observational study was conducted in compliance with the Japanese regulatory requirements of the GPSP (MHLW Ordinance No 171; December 20, 2004). Since the study protocol was reviewed and approved by the Japanese regulatory authority of PMDA prior to initiation, ethical review and approval were not required for the individual study sites. Informed consent was not obtained because Japanese regulations do not require informed consent for any post-marketing, non-interventional, observational studies conducted in accordance with the GPSP.

\section{Results \\ Patient demographics}

The number of NTG patients who started tafluprost treatment and were registered was 1,454 from 160 facilities from the registration period until December 2012. Of these, 1,353 patients were included in the safety analysis set, excluding 60 patients who failed to return after the first consultation, 31 patients whose case report forms could not be collected, 7 patients with registration criteria violations, and 3 patients who were not treated with tafluprost (Figure 1). The data from the safety analysis set were used for analyzing the onset of ADRs and treatment persistence rate. From the safety analysis set, 416 patients were included in the visual field analysis set, indicating that their IOP did not exceed $21 \mathrm{mmHg}$ at baseline and they had 5 or more visual field tests on a consistent measurement program measured using Humphrey perimeter.

Patient background data for these analysis sets are shown in Table 1.

No remarkable differences in patients' baseline characteristics were found between the safety analysis and visual field analysis sets.

In the visual field analysis set, $58.9 \%$ patients had ocular complications. Cataract/lens disorders were most commonly reported. Systemic complications were observed in 31.3\% of the patients. Hypertension was most commonly reported. The mean of the spherical equivalent was $-2.5 \pm 3.5 \mathrm{D}$, and $17.5 \%$ of the patients had a spherical equivalent of $\leq-6.0 \mathrm{D}$.

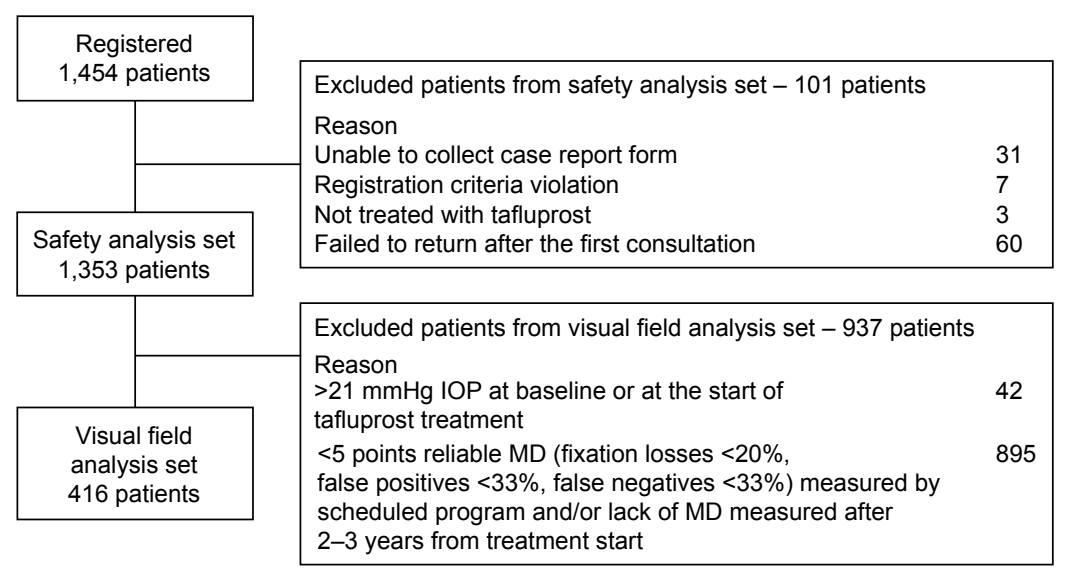

Figure I Patient flow diagram.

Abbreviations: IOP, intraocular pressure; MD, mean deviation. 
Table I Patient demographics

\begin{tabular}{|c|c|c|}
\hline Demographic & $\begin{array}{l}\text { Safety } \\
\text { analysis set }\end{array}$ & $\begin{array}{l}\text { Visual field } \\
\text { analysis set }\end{array}$ \\
\hline $\begin{array}{l}\text { Total number of patients } \\
\text { analyzed }\end{array}$ & I,353 & 416 \\
\hline \multicolumn{3}{|l|}{ Sex } \\
\hline Male & $594(43.9 \%)$ & I 86 (44.7\%) \\
\hline Female & 759 (56.1\%) & $230(55.3 \%)$ \\
\hline \multicolumn{3}{|l|}{ Age, years } \\
\hline Mean \pm SD & $65.2 \pm 12.6$ & $63.1 \pm 12.1$ \\
\hline Min-Max & $24-91$ & $28-88$ \\
\hline \multicolumn{3}{|l|}{ MD at baseline } \\
\hline Mean \pm SD & $-5.2 \pm 3.8 \mathrm{~dB}$ & $-5.3 \pm 4.0 \mathrm{~dB}$ \\
\hline$>-6 \mathrm{~dB}$ & 864 (63.9\%) & 269 (64.7\%) \\
\hline-6 to $-12 \mathrm{~dB}$ & 404 (29.9\%) & 117 (28.2\%) \\
\hline$<-12 \mathrm{~dB}$ & $85(6.3 \%)$ & 30 (7.2\%) \\
\hline \multicolumn{3}{|l|}{ IOP at baseline, $\mathrm{mmHg}$} \\
\hline Mean \pm SD & $15.0 \pm 3.1 \mathrm{mmHg}$ & $14.6 \pm 2.8 \mathrm{mmHg}$ \\
\hline$\leq 15$ & 777 (57.5\%) & $26 \mid(62.9 \%)$ \\
\hline$>15$ & 575 (42.5\%) & 154 (37.1\%) \\
\hline Unknown & 0 & 1 \\
\hline \multicolumn{3}{|l|}{ Spherical equivalent, D } \\
\hline Mean \pm SD & $-2 . I \pm 3.4 \mathrm{D}$ & $-2.5 \pm 3.5 \mathrm{D}$ \\
\hline$\leq-6.0$ & 174 (14.5\%) & $63(17.5 \%)$ \\
\hline$>-6.0$ & $\mathrm{I}, 023$ (85.5\%) & 296 (82.5\%) \\
\hline Unknown & 156 & 57 \\
\hline \multicolumn{3}{|c|}{ Concomitant ophthalmic disease (multiple entries) } \\
\hline None & $491(36.3 \%)$ & $17 \mid(41.1 \%)$ \\
\hline Vitreoretinal disease & $62(4.6 \%)$ & $9(2.2 \%)$ \\
\hline Cataract and lens disease & $737(54.5 \%)$ & $197(47.4 \%)$ \\
\hline Keratoconjunctival disease & $301(22.2 \%)$ & $94(22.6 \%)$ \\
\hline Eyelid and lacrimal disease & $16(1.2 \%)$ & $4(1.0 \%)$ \\
\hline Others & $38(2.8 \%)$ & II (2.6\%) \\
\hline \multicolumn{3}{|c|}{ Concomitant systemic disease (multiple entries) } \\
\hline None & $818(60.5 \%)$ & $286(68.8 \%)$ \\
\hline Hypertension & $299(22.1 \%)$ & $74(17.8 \%)$ \\
\hline Diabetes mellitus & |3| (9.7\%) & $26(6.3 \%)$ \\
\hline Migraine & $3(0.2 \%)$ & $\mathrm{I}(0.2 \%)$ \\
\hline Others & $251(18.6 \%)$ & $52(12.5 \%)$ \\
\hline \multicolumn{3}{|c|}{ Family history of glaucoma within second-degree relatives } \\
\hline Yes & $74(10.3 \%)$ & $26(10.0 \%)$ \\
\hline No & $647(89.7 \%)$ & $235(90.0 \%)$ \\
\hline Unknown & 632 & 155 \\
\hline \multicolumn{3}{|c|}{ Optic disc hemorrhage, including past history } \\
\hline Yes & $54(4.0 \%)$ & $16(3.8 \%)$ \\
\hline No & $1,296(96.0 \%)$ & $400(96.2 \%)$ \\
\hline Unknown & 3 & 0 \\
\hline
\end{tabular}

Abbreviations: IOP, intraocular pressure; MD, mean deviation.
Family history of glaucoma within the second-degree kins was found in $10.0 \%$ of the patients. A history of optic disc hemorrhage was found in $3.8 \%$ of the patients.

MDs at baseline are shown in Table 2. They were $-5.3 \pm 4.0 \mathrm{~dB}$ in all patients of the visual field analysis set, $-4.8 \pm 3.8 \mathrm{~dB}$ in naïve monotherapy, $-5.3 \pm 3.5 \mathrm{~dB}$ in switching monotherapy, and $-6.8 \pm 4.2 \mathrm{~dB}$ in concomitant therapy.

In switching monotherapy ( $\mathrm{n}=60$ ), the previous IOPlowering agents mainly comprised of latanoprost (58.3\%), travoprost (13.3\%), and unoprostone (8.3\%). In concomitant therapy ( $\mathrm{n}=93$ ), the concomitant agents mainly comprised of dorzolamide/timolol fixed-dose combination eye drops (31.2\%), timolol (20.4\%), brinzolamide (19.4\%), brimonidine (18.3\%), carteolol (17.2\%), and dorzolamide (11.8\%).

\section{ADRs}

Among the 1,353 patients included in the safety analysis set, 149 ADRs were found in 129 patients (9.53\%). No serious ADR was observed. Typical ADRs (\%) were eyelid pigmentation $(1.92 \%)$, ocular hyperemia $(1.33 \%)$, eyelash growth (1.26\%), eye itching $(0.59 \%)$, and blepharitis $(0.52 \%)$.

\section{Patients continuing tafluprost}

Figure 2 shows a patients continuing tafluprost in the safety analysis set.

Among the 1,353 patients included in the safety analysis set, 194 patients $(14.3 \%)$ discontinued tafluprost due to insufficient efficacy or safety reasons. There was progression of visual field loss in 34 patients (2.5\%), insufficient IOPlowering effect in 80 patients (5.9\%), and onset of ADRs in 80 patients $(5.9 \%)$. Due to lost to follow-up or any other reason other than the insufficient effectiveness and safety of tafluprost, 388 patients discontinued tafluprost.

The patients continuing tafluprost $(95 \% \mathrm{CI})$ in this study was $90.6 \%(88.8 \%-92.1 \%)$ for 12 months, $86.4 \%$ $(84.3 \%-88.2 \%)$ for 24 months, and $81.8 \%(79.0 \%-84.3 \%)$ for 36 months.

Table 2 MD slopes in differential analysis with treatment patterns in visual field analysis set

\begin{tabular}{|c|c|c|c|c|c|}
\hline & \multirow{2}{*}{$\begin{array}{l}\text { MD at baseline } \\
\text { (dB) }\end{array}$} & \multirow[t]{2}{*}{$\mathbf{n}$} & \multicolumn{2}{|c|}{ MD slope (dB/year) } & \multirow{2}{*}{$\begin{array}{l}\text { ANOVA } \\
\text { (P-value) }\end{array}$} \\
\hline & & & Mean \pm SD & $95 \% \mathrm{Cl}$ & \\
\hline Total & $-5.3 \pm 4.0$ & 416 & $-0.09 \pm 0.85$ & -0.17 to -0.01 & - \\
\hline Monotherapy & $-4.9 \pm 3.8$ & 323 & $-0.03 \pm 0.78$ & -0.11 to 0.06 & $0.004^{a}$ \\
\hline Naïve & $-4.8 \pm 3.8$ & 263 & $-0.02 \pm 0.80$ & -0.12 to 0.08 & $0.015^{b}$ \\
\hline Switching & $-5.3 \pm 3.5$ & 60 & $-0.07 \pm 0.68$ & -0.24 to 0.11 & \\
\hline Concomitant therapy & $-6.8 \pm 4.2$ & 93 & $-0.32 \pm 1.04$ & -0.53 to -0.10 & \\
\hline
\end{tabular}

Notes: ${ }^{a}$ Monotherapy vs concomitant therapy; ${ }^{b}$ naïve monotherapy vs switching monotherapy vs concomitant therapy.

Abbreviations: ANOVA, analysis of variance; MD, mean deviation. 


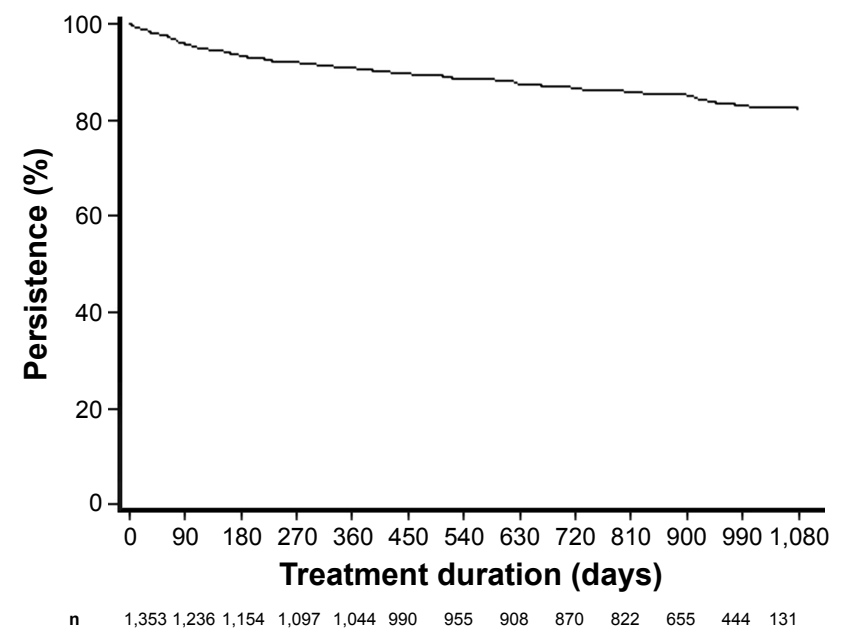

Figure 2 Patients continuing tafluprost treatment in 1,353 patients over the observational period of $2-3$ years by Kaplan-Meier curve.

Notes: A discontinuation of tafluprost treatment due to insufficient efficacy and safety reason is defined as an event.

\section{IOP}

Figure 3 shows changes in IOP in the visual field analysis set.

In the whole visual field analysis set, the mean IOPs were $14.5 \pm 2.9 \mathrm{mmHg}(\mathrm{n}=401), 12.8 \pm 2.4 \mathrm{mmHg}(\mathrm{n}=331$, $P<0.001), 12.8 \pm 2.2 \mathrm{mmHg}(\mathrm{n}=304, P<0.001)$, and $13.0 \pm 2.6 \mathrm{mmHg}(\mathrm{n}=142, P<0.001)$ at baseline, 12, 24, and 36 months of treatment, respectively. Significant IOP reduction was observed compared with the baseline throughout the observational period. In naïve monotherapy, the mean IOPs were $15.2 \pm 2.8 \mathrm{mmHg}(\mathrm{n}=251), 12.9 \pm 2.3 \mathrm{mmHg}$ (n=201, $P<0.001), 12.9 \pm 2.0 \mathrm{mmHg}(\mathrm{n}=182, P<0.001)$, and $13.0 \pm 2.6 \mathrm{mmHg}(\mathrm{n}=77, P<0.001)$ at baseline, 12, 24, and 36 months of treatment, respectively. In switching monotherapy, the mean IOPs were $12.5 \pm 2.1 \mathrm{mmHg}(\mathrm{n}=60)$, $12.2 \pm 2.2 \mathrm{mmHg}(\mathrm{n}=53, P=0.336), 12.2 \pm 1.7 \mathrm{mmHg}(\mathrm{n}=54$, $P=0.249)$, and $12.7 \pm 2.2 \mathrm{mmHg}(\mathrm{n}=29, P=0.439)$ at baseline, 12,24 , and 36 months of treatment, respectively. In concomitant therapy, the mean IOPs were $14.2 \pm 2.9 \mathrm{mmHg}(\mathrm{n}=90)$, $13.0 \pm 2.8 \mathrm{mmHg}(\mathrm{n}=77, P<0.001), 13.2 \pm 2.9 \mathrm{mmHg}(\mathrm{n}=68$, $P=0.002)$, and $13.5 \pm 2.9 \mathrm{mmHg}(\mathrm{n}=36, P=0.046)$ at baseline, 12,24 , and 36 months of treatment, respectively.

\section{MD slope in visual field}

In the 416 patients of the visual field analysis set, the mean times of a Humphrey visual field test satisfying all the reliability indices was $5.7 \pm 0.7$ times. The MD slope was $-0.09 \pm 0.85 \mathrm{~dB} /$ year. When the patients were divided into 3 treatment patterns, the MD slope was $-0.02 \pm 0.80 \mathrm{~dB} /$ year for naïve monotherapy, $-0.07 \pm 0.68 \mathrm{~dB} /$ year for switching monotherapy, and $-0.32 \pm 1.04 \mathrm{~dB} /$ year for concomitant therapy, with a significant difference $(P=0.015$; Table 2$)$. A significant difference was observed when MD slopes were analyzed in 3 subsets divided by MD at baseline: $>-6 \mathrm{~dB},-6$ to $-12 \mathrm{~dB}$, and $<-12 \mathrm{~dB}$ ( $P=0.014$; Table 3$)$.

In the naïve monotherapy group ( $\mathrm{n}=263)$, significant differences in MD slopes were observed in MD at baseline, IOP at baseline ( $>15 \mathrm{mmHg}$ vs $\leq 15 \mathrm{mmHg}$ ), and the presence/ absence of vitreoretinal disease (Table 4).

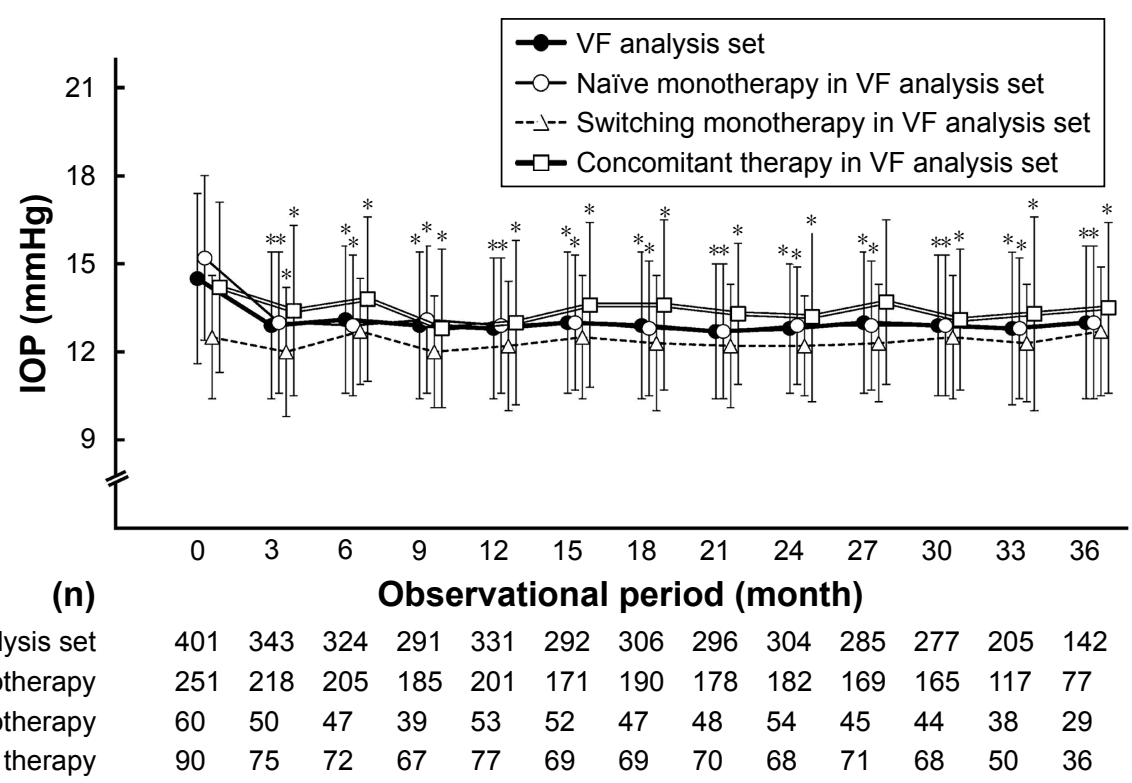

Figure 3 IOP in each analysis group.

Notes: IOP changes in all patients and each treatment pattern. IOPs were aggregated every 3 months from 0 to 36 months. Error bars indicate SD. $* P<0.05$ compared to IOP month 0 (paired $t$-test) in all treatment patterns.

Abbreviations: IOP, intraocular pressure; VF, visual field. 
Table 3 MD slopes in differential analyses in visual field analysis set

\begin{tabular}{|c|c|c|c|c|}
\hline & \multirow[t]{2}{*}{$\mathbf{N}$} & \multicolumn{2}{|c|}{ MD slope (dB/year) } & \multirow{2}{*}{$\begin{array}{l}\text { ANOVA } \\
\text { (P-value) }\end{array}$} \\
\hline & & Mean \pm SD & $95 \% \mathrm{Cl}$ & \\
\hline Total & 416 & $-0.09 \pm 0.85$ & -0.17 to -0.01 & - \\
\hline \multicolumn{5}{|l|}{ Sex } \\
\hline Male & 186 & $-0.06 \pm 0.84$ & -0.19 to 0.06 & \multirow[t]{2}{*}{0.548} \\
\hline Female & 230 & $-0.12 \pm 0.87$ & -0.23 to -0.00 & \\
\hline \multicolumn{5}{|l|}{ Age, years } \\
\hline$<65$ & 218 & $-0.05 \pm 0.76$ & -0.16 to 0.05 & \multirow[t]{2}{*}{0.348} \\
\hline$\geq 65$ & 198 & $-0.13 \pm 0.94$ & -0.27 to -0.00 & \\
\hline \multicolumn{5}{|l|}{ MD at baseline } \\
\hline$>-6 \mathrm{~dB}$ & 269 & $-0.13 \pm 0.70$ & -0.21 to -0.04 & \multirow[t]{3}{*}{0.014} \\
\hline-6 to $-12 \mathrm{~dB}$ & 117 & $0.07 \pm 1.08$ & -0.13 to 0.27 & \\
\hline$<-12 \mathrm{~dB}$ & 30 & $-0.40 \pm 1.00$ & -0.77 to -0.02 & \\
\hline \multicolumn{5}{|c|}{ IOP at baseline (unknown: I patient), mmHg } \\
\hline$\leq 15$ & 261 & $-0.11 \pm 0.83$ & -0.21 to -0.01 & \multirow[t]{2}{*}{0.446} \\
\hline$>15$ & 154 & $-0.04 \pm 0.88$ & -0.18 to 0.09 & \\
\hline \multicolumn{5}{|c|}{ IOP reduction (not applicable: I5 patients), \% } \\
\hline$\geq 20$ & 88 & $-0.04 \pm 0.88$ & -0.22 to 0.15 & \multirow[t]{4}{*}{0.085} \\
\hline$\geq 10,<20$ & 112 & $-0.00 \pm 0.78$ & -0.15 to 0.14 & \\
\hline$\geq 0,<10$ & 108 & $-0.06 \pm 0.87$ & -0.22 to 0.11 & \\
\hline$<0$ & 93 & $-0.29 \pm 0.87$ & -0.47 to -0.11 & \\
\hline \multicolumn{5}{|c|}{ Spherical equivalent (unknown: 57 patients), D } \\
\hline$\leq-6.0$ & 63 & $-0.12 \pm 0.80$ & -0.33 to 0.08 & \multirow[t]{2}{*}{0.685} \\
\hline$>-6.0$ & 296 & $-0.08 \pm 0.84$ & -0.17 to 0.02 & \\
\hline \multicolumn{5}{|c|}{ Concomitant ophthalmic disease } \\
\hline No & 171 & $-0.11 \pm 0.69$ & -0.21 to -0.00 & \multirow[t]{2}{*}{0.753} \\
\hline Yes & 245 & $-0.08 \pm 0.95$ & -0.20 to 0.04 & \\
\hline Vitreoretinal $d$ & & & & \\
\hline No & 407 & $-0.10 \pm 0.84$ & -0.19 to -0.02 & 0.054 \\
\hline Yes & 9 & $0.45 \pm 1.24$ & -0.50 to 1.40 & \\
\hline Cataract and le & & & & \\
\hline No & 219 & $-0.08 \pm 0.7 \mid$ & -0.18 to 0.01 & 0.829 \\
\hline Yes & 197 & $-0.10 \pm 0.99$ & -0.24 to 0.04 & \\
\hline Keratoconjunc & & & & \\
\hline No & 322 & $-0.11 \pm 0.86$ & -0.21 to -0.02 & 0.405 \\
\hline Yes & 94 & $-0.03 \pm 0.84$ & -0.20 to 0.14 & \\
\hline Eyelid and lacri & & & & \\
\hline No & 412 & $-0.09 \pm 0.86$ & -0.18 to -0.01 & 0.573 \\
\hline Yes & 4 & $0.15 \pm 0.41$ & -0.51 to 0.80 & \\
\hline Concomitant syst & & & & \\
\hline No & 286 & $-0.1 I \pm 0.84$ & -0.20 to -0.01 & 0.599 \\
\hline Yes & 130 & $-0.06 \pm 0.89$ & -0.21 to 0.10 & \\
\hline Hypertension & & & & \\
\hline No & 342 & $-0.09 \pm 0.82$ & -0.18 to -0.00 & 0.989 \\
\hline Yes & 74 & $-0.09 \pm 1.00$ & -0.33 to 0.14 & \\
\hline Diabetes mellit & & & & \\
\hline No & 390 & $-0.10 \pm 0.85$ & -0.18 to -0.01 & 0.505 \\
\hline Yes & 26 & $0.02 \pm 0.84$ & -0.33 to 0.36 & \\
\hline Migraine & & & & \\
\hline No & 415 & $-0.09 \pm 0.85$ & -0.17 to -0.01 & 0.677 \\
\hline Yes & 1 & -0.45 & - & \\
\hline Family history of & relative & patients) & & \\
\hline No & 235 & $-0.15 \pm 0.79$ & -0.25 to -0.04 & 0.206 \\
\hline Yes & 26 & $0.14 \pm 0.79$ & -0.18 to 0.46 & \\
\hline Optic disc hemor & & & & \\
\hline No & 400 & $-0.09 \pm 0.85$ & -0.18 to -0.01 & 0.818 \\
\hline Yes & 16 & $-0.04 \pm 0.85$ & -0.50 to $0.4 \mathrm{I}$ & \\
\hline Optic disc hemor & & & & \\
\hline No & 387 & $-0.10 \pm 0.86$ & -0.18 to -0.01 & 0.697 \\
\hline Yes & 29 & $-0.03 \pm 0.84$ & -0.35 to 0.29 & \\
\hline
\end{tabular}

Abbreviations: ANOVA, analysis of variance; IOP, intraocular pressure; MD, mean deviation. 
Table 4 MD slopes in naïve monotherapy patients of the visual field analysis set

\begin{tabular}{|c|c|c|c|c|}
\hline & \multirow[t]{2}{*}{$n$} & \multicolumn{2}{|c|}{ MD slope (dB/year) } & \multirow{2}{*}{$\begin{array}{l}\text { ANOVA } \\
\text { (P-value) }\end{array}$} \\
\hline & & Mean \pm SD & $95 \% \mathrm{Cl}$ & \\
\hline Total & 263 & $-0.02 \pm 0.80$ & -0.12 to 0.08 & - \\
\hline \multicolumn{5}{|l|}{ Sex } \\
\hline Male & 117 & $-0.0 \mathrm{I} \pm 0.74$ & -0.14 to 0.13 & \multirow[t]{2}{*}{0.825} \\
\hline Female & 146 & $-0.03 \pm 0.85$ & -0.17 to 0.11 & \\
\hline \multicolumn{5}{|l|}{ Age, years } \\
\hline$<65$ & 135 & $-0.02 \pm 0.65$ & -0.13 to 0.09 & \multirow[t]{2}{*}{0.962} \\
\hline$\geq 65$ & 128 & $-0.02 \pm 0.94$ & -0.19 to 0.14 & \\
\hline \multicolumn{5}{|c|}{ MD at baseline, $\mathrm{dB}$} \\
\hline$>-6$ & 183 & $-0.07 \pm 0.65$ & -0.16 to 0.03 & \multirow[t]{3}{*}{$<0.001$} \\
\hline-6 to -12 & 63 & $0.26 \pm 1.00$ & 0.01 to $0.5 \mathrm{I}$ & \\
\hline$<-12$ & 17 & $-0.52 \pm 1.14$ & $-I . I I$ to 0.07 & \\
\hline \multicolumn{5}{|c|}{ IOP at baseline, $\mathrm{mmHg}$} \\
\hline$\leq 15$ & 148 & $-0.10 \pm 0.82$ & -0.24 to 0.03 & \multirow[t]{2}{*}{0.049} \\
\hline$>15$ & 115 & $0.09 \pm 0.77$ & -0.05 to 0.23 & \\
\hline \multicolumn{5}{|c|}{ Spherical equivalent (unknown: 19 patients), D } \\
\hline$\leq-6.0$ & 42 & $0.07 \pm 0.76$ & -0.17 to 0.30 & \multirow[t]{2}{*}{0.536} \\
\hline$>-6.0$ & 202 & $-0.02 \pm 0.79$ & -0.13 to 0.09 & \\
\hline \multicolumn{5}{|c|}{ Concomitant ophthalmic disease } \\
\hline No & 114 & $-0.04 \pm 0.63$ & -0.16 to 0.07 & \multirow[t]{2}{*}{0.646} \\
\hline Yes & 149 & $0.00 \pm 0.91$ & -0.15 to 0.15 & \\
\hline \multicolumn{5}{|c|}{ Vitreoretinal disease } \\
\hline No & 257 & $-0.03 \pm 0.78$ & -0.13 to 0.06 & \multirow[t]{2}{*}{0.037} \\
\hline Yes & 6 & $0.66 \pm 1.37$ & -0.78 to 2.10 & \\
\hline \multicolumn{5}{|c|}{ Cataract and lens disease } \\
\hline No & 150 & $-0.02 \pm 0.67$ & -0.13 to 0.09 & \multirow[t]{2}{*}{0.964} \\
\hline Yes & 113 & $-0.02 \pm 0.95$ & -0.20 to 0.16 & \\
\hline Keratocon & & & & \\
\hline No & 210 & $-0.02 \pm 0.82$ & -0.13 to 0.10 & 0.891 \\
\hline Yes & 53 & $-0.03 \pm 0.72$ & -0.23 to 0.17 & \\
\hline Eyelid and & & & & \\
\hline No & 260 & $-0.02 \pm 0.8 \mathrm{I}$ & -0.12 to 0.08 & 0.629 \\
\hline Yes & 3 & $0.20 \pm 0.48$ & -1.00 to 1.41 & \\
\hline Concomitant & & & & \\
\hline No & 185 & $-0.06 \pm 0.77$ & -0.17 to 0.05 & 0.242 \\
\hline Yes & 78 & $0.07 \pm 0.88$ & -0.13 to 0.27 & \\
\hline Hypertensi & & & & \\
\hline No & 217 & $-0.05 \pm 0.77$ & -0.15 to 0.06 & 0.225 \\
\hline Yes & 46 & $0.11 \pm 0.93$ & -0.16 to 0.39 & \\
\hline Diabetes $\mathrm{m}$ & & & & \\
\hline No & 250 & $-0.04 \pm 0.8 \mathrm{I}$ & -0.14 to 0.06 & 0.125 \\
\hline Yes & 13 & $0.3 \mathrm{I} \pm 0.5 \mathrm{I}$ & 0.01 to 0.62 & \\
\hline Migraine & & & & \\
\hline No & 262 & $-0.02 \pm 0.80$ & -0.11 to 0.08 & 0.593 \\
\hline Yes & 1 & -0.45 & - & \\
\hline Family history & elative & patients) & & \\
\hline No & 155 & $-0.08 \pm 0.77$ & -0.20 to 0.04 & 0.229 \\
\hline Yes & 18 & $0.21 \pm 0.92$ & -0.25 to 0.66 & \\
\hline Optic disc he & & & & \\
\hline No & 252 & $-0.03 \pm 0.80$ & -0.13 to 0.07 & 0.521 \\
\hline Yes & 11 & $0.13 \pm 0.80$ & $-0.4 \mid$ to 0.67 & \\
\hline Optic disc he & & & & \\
\hline No & 250 & $-0.02 \pm 0.81$ & -0.12 to 0.08 & 0.661 \\
\hline Yes & 13 & $0.08 \pm 0.73$ & -0.37 to 0.52 & \\
\hline
\end{tabular}

Abbreviations: ANOVA, analysis of variance; IOP, intraocular pressure; MD, mean deviation.

The relationship between $\% \mathrm{IOP}$ reduction after treatment and MD slope was also evaluated in the naïve monotherapy group. Table 5 shows MD slopes when patients were divided into 4 subsets by $\% \mathrm{IOP}$ reduction after treatment in units of
$10 \%$ and into 2 subsets by $10 \%$ IOP reduction after treatment. Significant differences were observed in both subset analyses ( $P=0.001$ in both). When patients were divided into 2 groups by $10 \%$ IOP reduction after treatment, the mean MD slope 
Table 5 MD slopes in differential analysis with \% IOP reduction in naïve-monotherapy patients of the visual field analysis set

\begin{tabular}{|c|c|c|c|c|}
\hline & \multirow[t]{2}{*}{$\mathbf{n}$} & \multicolumn{2}{|c|}{ MD slope (dB/year) } & \multirow{2}{*}{$\begin{array}{l}\text { ANOVA } \\
\text { (P-value) }\end{array}$} \\
\hline & & Mean \pm SD & $95 \% \mathrm{Cl}$ & \\
\hline Total & 263 & $-0.02 \pm 0.80$ & -0.12 to 0.08 & - \\
\hline \multicolumn{5}{|c|}{ IOP reduction, \% } \\
\hline \multicolumn{5}{|c|}{ Four categories in units of $10 \%$} \\
\hline$\geq 20$ & 75 & $0.05 \pm 0.79$ & -0.13 to 0.23 & 0.001 \\
\hline$\geq 10$ to $<20$ & 74 & $0.18 \pm 0.67$ & 0.03 to 0.34 & \\
\hline$\geq 0$ to $<10$ & 67 & $-0.1 I \pm 0.78$ & -0.30 to 0.08 & \\
\hline$<0$ & 35 & $-0.45 \pm 1.00$ & -0.79 to 0.11 & \\
\hline \multicolumn{5}{|c|}{ Two categories, \% } \\
\hline$\geq 10$ & 149 & $0.11 \pm 0.73$ & -0.00 to 0.23 & 0.001 \\
\hline$<10$ & 102 & $-0.22 \pm 0.87$ & -0.39 to 0.05 & \\
\hline
\end{tabular}

Note: IOP reduction could not be calculated in 12 patients. Abbreviations: ANOVA, analysis of variance; IOP, intraocular pressure; MD, mean deviation.

was $0.11 \pm 0.73 \mathrm{~dB} /$ year for $10 \%$ IOP reduction or higher and $-0.22 \pm 0.87 \mathrm{~dB} /$ year for $<10 \%$ reduction.

\section{Discussion}

In this study, the effectiveness of tafluprost in Japanese NTG patients was evaluated in actual daily clinical practice settings over an observational period of 2-3 years. After tafluprost treatment initiation, IOP was reduced and was stably maintained throughout the observational period in all treatment patterns.

Tafluprost showed sufficient effectiveness in reducing visual field progression to a mean MD slope of $-0.09 \pm 0.85 \mathrm{~dB} /$ year. Although the above data cannot be directly compared with that of other studies, the progression of visual field loss in untreated glaucoma patients was $-0.778 \pm 0.178 \mathrm{~dB} /$ year (mean $\pm \mathrm{SE}$ ) in Japanese NTG patients. ${ }^{13}$ The CNTGS reported it to be $-0.4018 \pm 3.65 \mathrm{~dB} /$ year $($ mean $\pm \mathrm{SD}){ }^{6}$

The mean MD slopes by treatment pattern were as follows: $-0.02 \pm 0.80 \mathrm{~dB} /$ year for naïve monotherapy, $-0.07 \pm 0.68 \mathrm{~dB} /$ year for switching monotherapy, and $-0.32 \pm 1.04 \mathrm{~dB} /$ year for concomitant therapy. The visual fields were stable in the naïve and switching monotherapy groups. The MD slopes were significantly different among naïve monotherapy, switching monotherapy, and concomitant therapy groups. The reason for this difference was considered to be the inclusion of a higher percentage of patients with advanced visual field loss in the concomitant therapy group according to the MD at baseline.

With regard to other literature reports on visual field progression in NTG patients under drug treatment, Tomita et al reported that the MD slope was $-0.34 \pm 0.17 \mathrm{~dB} /$ year (mean \pm $\mathrm{SE})$ for the latanoprost group and $-0.10 \pm 0.18 \mathrm{~dB} /$ year (mean $\pm \mathrm{SE}$ ) for the timolol group in a comparative study on visual fields measured every 6 months for 3 years. ${ }^{14}$

The relationship between IOP reduction and visual field progression under treatment by tafluprost in naïve monotherapy was examined. The visual field progression was significantly slower in the group of $10 \%$ IOP reduction or higher than the group of $<10 \%$ IOP reduction. In CNTGS, patients with 30\% IOP reduction showed a slower rate of visual field progression than untreated patients. ${ }^{6}$ Early Manifest Glaucoma Trial (EMGT) suggested that $1 \mathrm{mmHg}$ IOP reduction showed an $\sim 10 \%$ decreased risk of visual field progression. ${ }^{5}$ Our data regarding Japanese NTG patients suggested that a small IOP reduction affects visual field progression beneficially.

In addition to the involvement of IOP reduction in visual field progression, there is a hypothesis that glaucoma progression could be suppressed through optic nerve head protection by ensuring adequate blood flow to the optic nerve, although no definitive medical evidence is available at this time. Meng et al reported that there were changes in various parameters indicating reduction of ocular arterial circulation in primary open-angle glaucoma (POAG) patients by color Doppler imaging (CDI) of the retrobulbar vessels, and this suggests that CDI may serve as a diagnostic tool for POAG, based on meta-analysis of data from the literature up to October $2012 .{ }^{15}$ With regard to tafluprost, there are several reports on its effect on ocular blood flow. Tsuda et al reported that when ocular circulation was measured using laser speckle flowgraphy after a single tafluprost instillation in myopic optic nerve disc patients, optic nerve head blood circulation increased. ${ }^{16}$ Kojima et al reported that tafluprost treatment for 1 year in POAG patients not only improved the MD but also improved the microcirculation of the optic nerve head in the superior and inferior sectors, as seen by laser speckle flowgraphy. ${ }^{17}$

Moreover, in this study, significant differences in MD slope were observed when we analyzed it among different IOPs at baseline $(0.09 \mathrm{~dB} /$ year in $>15 \mathrm{mmHg},-0.10 \mathrm{~dB} /$ year in $\leq 15 \mathrm{mmHg}$ ). IOP reductions were $21.9 \%$ in $>15 \mathrm{mmHg}$ and $6.3 \%$ in $\leq 15 \mathrm{mmHg}$ at 24 months. It suggested that a higher IOP reduction will contribute to visual field progression. Significant differences in visual field progression were also observed in the patients at an early glaucoma stage categorized by MD at baseline. This suggested that the diagnosis of glaucoma at an early stage would be effective for the future outcomes.

Although this study was non-interventional and observational, strict criteria were set to include only the patients with MD who met the reliability indices at 5 time points or more for visual field measurements in a period of 2-3 years. 
The linear regression analysis can account for fluctuations in visual field measurement at various time points. Chauhan et al suggested that 3 examinations per year are required to identify an overall change in MD of $4 \mathrm{~dB}$ over 2 years in a patient with average visual field variability. ${ }^{18}$ Our study collected data for 416 patients from multiple medical institutions to analyze the MD slope under the strict condition that needed 5 time points or more for visual field measurements in a period of 2-3 years.

On the other hand, there are limitations to this study. The visual field trend analysis requires a sufficiently long observational period ( $2-3$ years), and analysis of therapeutic effect and background characteristics requires sufficient data regarding patients who successfully maintained sufficient visual field on monotherapy. Therefore, there is a bias in including only patients who responded well to tafluprost, whereas patients who did not respond well and were lost to follow-up were not included in the analysis. However, the tafluprost treatment persistence in the present study was $86.4 \%$ for 24 months, which was similar to the data reported in another observational, non-interventional study. ${ }^{12}$ There was no noticeable difference in patient backgrounds between the visual field analysis and safety analysis sets.

The total disconsolation rate of $43.0 \%$ was high. However, other studies have reported similar discontinuation rates in daily clinical settings. Kashiwagi and Furuya investigated glaucoma medication adherence in daily clinical settings via the Japanese Health Insurance Society database. ${ }^{19}$ In the analysis, the persistence rate was $52.5 \%$ at 3 years after the initiation, when discontinuation of glaucoma medication was defined as no record of a glaucoma medication prescription or monthly claims for medical expenses for 6 months or longer. The result was similar to that in our study. Therefore, the high rate of discontinuation shown in our study is not unique to our study compared to actual daily use in a clinical setting.

In our study, $47.4 \%$ of patients had a concomitant cataract and lens disease. In general, the population tends to be older, and there was a concern that the progression of cataract may impact the visual field examination. Therefore, on the basis of the safety data, secondary visual field progression analysis was conducted by excluding all the visual field data that were obtained after onset of cataract progression. The analysis showed that in the whole visual field analysis set, 409 patients showed a visual field progression of $-0.10 \pm 0.83 \mathrm{~dB} /$ year. In naïve monotherapy patients within the visual field analysis set, 259 patients showed a visual field progression of $-0.02 \pm 0.80 \mathrm{~dB} /$ year. These results were equivalent to the visual field data collected after the onset of cataract progression.

\section{Conclusion}

An at least $10 \%$ IOP reduction with tafluprost monotherapy in $56.7 \%$ of the treatment-naïve NTG eyes was sufficient to significantly reduce the MD rate of progression compared to that of eyes showing $<10 \%$ IOP reduction.

\section{Data availability}

The datasets during and/or analyzed during the current study are available from the corresponding author on reasonable request.

\section{Acknowledgments}

Sponsorship and article processing charges for this study were funded by Santen Pharmaceutical Co., Ltd., Osaka, Japan. We wish to express our gratitude to the physicians at the medical institutions who cooperated in the study.

\section{Author contributions}

All authors contributed toward data analysis, drafting and revising the paper and agree to be accountable for all aspects of the work.

\section{Disclosure}

Akio Nomura, Hirotaka Osaki, and Fumiki Shimada are employees of Santen Pharmaceutical Co., Ltd. Yasuaki Kuwayama is a consultant for Alcon Japan, Kowa Company, Ltd., Otsuka Pharmaceutical, Pfizer Japan, Santen Pharmaceutical, and Senju Pharmaceutical, and has received speaker honoraria from Alcon Japan, Kowa Company, Ltd., Otsuka Pharmaceutical, Pfizer Japan, Santen Pharmaceutical, Senju Pharmaceutical. The authors report no other conflicts of interest in this work.

\section{References}

1. Iwase A, Suzuki Y, Araie M, et al. The prevalence of primary open-angle glaucoma in Japanese: the Tajimi Study. Ophthalmology. 2004;111: 1641-1648.

2. Yamamoto T, Iwase A, Araie M, et al. The Tajimi Study Report 2: prevalence of primary angle closure and secondary glaucoma in a Japanese population. Ophthalmology. 2005;112:1661-1669.

3. Heijl A, Leske MC, Bengtsson B, et al. Reduction of intraocular pressure and glaucoma progression: results from the Early Manifest Glaucoma Trial. Arch Ophthalmol. 2002;120:1268-1279.

4. Agis Investigators. The Advanced Glaucoma Intervention Study (AGIS): 7. The relationship between control of intraocular pressure and visual field deterioration. The AGIS Investigators. Am J Ophthalmol. 2000; 130:429-440.

5. Leske MC, Heijl A, Hussein M, et al. Factors for glaucoma progression and the effect of treatment: the Early Manifest Glaucoma Trial. Arch Ophthalmol. 2003;121:48-56.

6. Collaborative Normal Tension Glaucoma Study Group. Comparison of glaucomatous progression between untreated patients with normaltension glaucoma and patients with therapeutically reduced intraocular pressures. Am J Ophthalmol. 1998;126:487-497. 
7. Suzuki K. An update review of medical treatment in normal-tension glaucoma. Atarashi Iganka. 2016;33:35-43.

8. Tomidokoro A. Clinical application of glaucoma medications. Folia Pharmacol Jpn. 2006;128:255-258.

9. Marquis RE, Whitson JT. Management of glaucoma: focus on pharmacological therapy. Drugs Aging. 2005;22:1-21.

10. Kuwayama Y, Komemushi S; Tafluprost Multi-center Study Group. Intraocular pressure lowering effect of $0.0015 \%$ tafluprost as compared to placebo in patients with normal tension glaucoma: randomized, double-blind, multicenter, phase III study. Nippon Ganka Gakkai Zasshi. 2010;114:436-443.

11. Kuwayama Y, Nomura A. Prospective observational post-marketing study of tafluprost for glaucoma and ocular hypertension: short-term efficacy and safety. Adv Ther. 2014;31:461-471.

12. Kuwayama Y, Hashimoto M, Kakegawa R, Nomura A, Shimada F. Prospective observational post-marketing study of tafluprost for glaucoma and ocular hypertension: effectiveness and treatment persistence. Adv Ther. 2017;34:1411-1425.

13. Koseki N, Araie M, Yamagami J, Shirato S, Yamamoto S. Effects of oral brovincamine on visual field damage in patients with normaltension glaucoma with low-normal intraocular pressure. J Glaucoma. 1999;8:117-123.
14. Tomita G, Araie M, Kitazawa Y, Tsukahara S. A three-year prospective, randomized and open comparison between latanoprost and timolol in Japanese normal-tension glaucoma patients. Eye. 2004;18: 984-989.

15. Meng N, Zhang P, Huang H, et al. Color Doppler imaging analysis of retrobulbar blood flow velocities in primary open-angle glaucomatous eyes: a meta-analysis. PLoS One. 2013;8:e62723.

16. Tsuda S, Yokoyama Y, Chiba N, et al. Effect of topical tafluprost on optic nerve head blood flow in patients with myopic disc type. J Glaucoma. 2013;22:398-403.

17. Kojima S, Sugiyama T, Shibata M, Ueki M, Komoto R, Ikeda T. Changes in visual field, morphology and microcirculation of the optic nerve head after instillation of tafluprost for one year. Jpn J Clin Ophthalmol. 2014;68:895-902.

18. Chauhan BC, Garway-Heath DF, Goni FJ, et al. Practical recommendations for measuring rates of visual field change in glaucoma. $\mathrm{Br} J$ Ophthalmol. 2008;92:569-573.

19. Kashiwagi K, Furuya T. Persistence with topical glaucoma therapy among newly diagnosed Japanese patients. Jpn J Ophthalmol. 2014; 58:68-74.
Clinical Ophthalmology

\section{Publish your work in this journal}

Clinical Ophthalmology is an international, peer-reviewed journal covering all subspecialties within ophthalmology. Key topics include: Optometry; Visual science; Pharmacology and drug therapy in eye diseases; Basic Sciences; Primary and Secondary eye care; Patient Safety and Quality of Care Improvements. This journal is indexed on

\section{Dovepress}

PubMed Central and CAS, and is the official journal of The Society of Clinical Ophthalmology (SCO). The manuscript management system is completely online and includes a very quick and fair peer-review system, which is all easy to use. Visit http://www.dovepress.com/ testimonials.php to read real quotes from published authors. 